\title{
O ENSINO DA MAQUIAGEM TEATRAL
}

\author{
Olívia Camboim Romano (UFS) 1 \\ Doutora em Artes Cênicas \\ Rua Barão de Loreto, 33, apto. 602, Ed. Joanes, Graça. Salvador - BA. 40150-270 \\ (71) 98178.7979 \\ camboim.olivia@gmail.com
}

\section{INTRODUÇÃO}

\begin{abstract}
A maquiagem da personagem prevê alguma transformação. Apontamentos sobre diferenças entre a idade do ator e da personagem, a saúde ou ponto de vista sobre a vida constitui uma mudança de caráter, de personalidade, e a maquiagem teatral deve refletir isso (Bert Broe,1984, p. 27, tradução nossa).
\end{abstract}

Entre os anos de 2007 e 2011 assumi na Universidade Regional de Blumenau (Furb) o componente curricular Maquiagem e Caracterização, na ocasião, obrigatório na terceira fase do antigo curso Artes Bacharelado em Teatro - Interpretação, cuja ementa consistia em "A função da maquiagem e da caracterização no teatro. Os elementos da maquiagem e suas funções. Teorias e técnicas da maquiagem teatral. Criação e técnicas de confecção de elementos postiços da maquiagem".

Com a finalidade de atender a ementa supracitada, o programa do componente contemplou abordagens teóricas, estéticas e históricas relacionadas à maquiagem e à caracterização; um trabalho prático e técnico relativo aos elementos, fundamentos e funções da maquiagem teatral, ao domínio da automaquiagem, à pratica de diversos tipos de maquiagem, tais como: básica e social, envelhecimento, palhaços, animalização, oriental, ferimentos e efeitos especiais, como ocultamento das sobrancelhas, entre outros; bem como, a confecção de uma face cast, ou seja, um molde (positivo e negativo) do rosto de cada estudante. Na época, essa face cast foi utilizada como suporte para a elaboração de máscaras neutras, utilizadas para treinamento do ator, no semestre seguinte, em Interpretação Teatral III, ministrada por mim; mas esses moldes também poderiam ter sido utilizados para a elaboração de alguns elementos postiços de maquiagem teatral com látex, por exemplo, e, evidentemente, como suporte para a confecção de outras máscaras (expressivas, larvárias etc.). Além das abordagens mencionadas acima, a ementa também pedia a elaboração e execução de um projeto de maquiagem e caracterização para um personagem dramático de uma peça teatral. Em consonância com

\footnotetext{
1 Doutora em Artes Cênicas pela Universidade Federal da Bahia (2018), Mestre em Teatro (2005) e Graduada em Licenciatura Educação Artística - Habilitação Artes Cênicas (2002) pela Universidade do Estado de Santa Catarina. Integra o corpo docente efetivo da Universidade Federal de Sergipe (UFS) desde agosto de 2018; sendo que, entre os anos de 2006 e 2018, foi professora na Universidade Regional de Blumenau (FURB). Autora do livro Uma arena no museu: reflexões sobre a primeira montagem de Brecht em Santa Catarina (Edifurb, 2010).
} 
uma perspectiva interdisciplinar, esse projeto era elaborado em comum acordo com o componente Interpretação Teatral II, na época também ministrado por mim, em que uma peça teatral, escolhida consensualmente entre os estudantes matriculados regularmente e a professora, era tomada como referência para a sua elaboração.

Cabe mencionar, no que diz respeito à relação entre a maquiagem e a máscara no teatro ocidental, que, numa perspectiva histórica, as máscaras da antiguidade grega são antecessoras da maquiagem teatral, conforme afirma o professor José Roberto Sampaio (Roberto Laplane):

Desde a máscara do antigo teatro grego, que era carregada de elementos, cujas funções primordiais eram ampliar as expressões visuais e vocais do ator, devido à distância entre o palco e a plateia, é possível identificar semelhanças entre esta e a maquiagem teatral. Essa afirmação é sustentada pelo fato de que algumas estéticas de teatro, desde o seu surgimento na Grécia, há mais de dois mil anos, utilizavam a máscara, um elemento cênico colocado no rosto dos atores, com as suas devidas funções. $\mathrm{Na}$ maquiagem, acontece o mesmo. A sua concepção para um espetáculo deve atender às necessidades estéticas da encenação, a partir das informações do texto a ser montado e o conceito da encenação. (2015, p. 71)

Cabe ressaltar que o caminho metodológico escolhido para as aulas de maquiagem foi a automaquiagem. Tal escolha deveu-se ao fato de que, no futuro exercício de suas profissões, provavelmente, apenas em produções de grande porte os atores poderão contar com um maquiador profissional. Mesmo em grandes produções, há trabalhos em que os atores preparam seu próprio rosto e o maquiador finaliza as maquiagens; há casos em que o encenador e/ou o maquiador elaboram o projeto de maquiagem e os atores 0 executam no decorrer da temporada; outras vezes, um dos atores, com maior conhecimento do assunto, assume o papel de maquiador e auxilia os demais membros do elenco; há ainda situações, não tão raras, em que os atores assumem integralmente o projeto e a execução da maquiagem. Assim, o domínio da automaquiagem é fundamental aos atores; pois, as cores, formas e as texturas das maquiagens e dos demais aspectos visuais do espetáculo, como cenários e figurinos, intervém no espaço cênico; portanto, todos esses elementos devem estar integrados a ele.

Considerando que alguns atores de formação também trabalharão como maquiadores profissionais, como é o caso, por exemplo, de Kriséven Campana² (egressa da FURB), o cronograma de Maquiagem e Caracterização, entre os anos de 2007 e 2011, também contemplou momentos em que os estudantes, divididos

\footnotetext{
${ }^{2}$ Após formada em Bacharelado em Artes - Interpretação, ela trabalhou alguns anos em Blumenau como maquiadora profissional em salão de beleza e emissora de televisão, atuando, inclusive em desfiles de moda e campanhas eleitorais. Desde 2017, atua como maquiadora em eventos particulares, como casamentos e ensaios fotográficos.
} 
em duplas, executaram um projeto de maquiagem no rosto de um outro colega de turma. Mas, prevaleceu a automaquiagem, uma vez que esta estratégia metodológica permite, dentre outras questões, que os estudantes adquiram as maquiagens básicas das marcas por eles próprios escolhidas, no tom de sua própria pele. Sendo que, é recomendado que os estudantes façam testes alérgicos com todos os produtos que utilizarão nas aulas no ato da aquisição. Além disso, a automaquiagem confere aos estudantes maior liberdade para manipularem seus produtos com a ponta de seus dedos e dispensarem o uso de alguns pincéis, o que não seria possível, por questões de higiene, se todos os exercícios praticados em sala de aula fossem efetuados no rosto de outro colega de turma; pois isso, obrigatoriamente, demandaria o uso exclusivo de pincéis, bem como a limpeza e secagem adequada dos materiais após a realização de cada exercício.

\section{OS CINCO PRINCIPAIS DESAFIOS E AS ESTRATÉGIAS DE ENFRENTAMENTO}

A aquisição dos produtos necessários para as aulas de maquiagem é o primeiro grande desafio desse componente curricular, pois, em primeiro lugar, eles têm o custo relativamente elevado. Em segundo lugar, são materiais de consumo, ou seja, com duração limitada a um curto lapso de tempo. Em terceiro lugar, é muito difícil para a Universidade adquirir com frequência uma paleta de cores de todas as maquiagens de forma que contemple os diferentes tons de pele de todos os estudantes matriculados. Dessa forma, foi imprescindível que cada estudante regularmente matriculado em Maquiagem e Caracterização efetuasse 0 investimento de adquirir seu próprio conjunto de maquiagem.

O conjunto pessoal de maquiagem, conforme solicitado aos estudantes, deve conter, no mínimo, os seguintes itens básicos: base (líquida ou em bastão, na tonalidade de sua pele); corretivo (líquido ou em bastão, na tonalidade de sua pele); pó facial compacto ou solto (na tonalidade de sua pele); lápis de olho (branco, tons de marrom e preto); máscara ou gel para os cílios (preto e/ou transparente); sombra em pó matte/fosca (tons de marrom, branco, bege e preto); sombra em pó em cores diversas e vibrantes; lápis de boca (vermelho e nude/cor de boca); blush compacto (tons de marrom); batom (cor de boca e outras tonalidades); tinta facial (color make ou clown make) nas cores branco, preto, vermelho e amarelo; pan cakes (branco e outras cores). Além disso, cada conjunto deve conter os seguintes artefatos: esponjas (para aplicação de base líquida, pan cake e pó facial); pincéis (para aplicação de pó solto; blush, sombra e batom); apontador para lápis de maquiagem; cola escolar em bastão; escova para sobrancelhas; sabonete neutro para o rosto; demaquilante; cotonetes; algodões; toalha para o rosto e um pote pequeno para água 3 .

\footnotetext{
${ }^{3}$ Além desses materiais indispensáveis, há uma série de artigos complementares opcionais, tais como: avental para proteger a roupa, cílios postiços, cola de cílios, cola para postiços, corretivos coloridos, creme hidratante facial; curvex, estojo de lápis de cor aquarela
} 
Uma estratégia possível para reduzir um pouco os custos com a aquisição de maquiagens é a produção de alguns produtos artesanais, cujas receitas levam ingredientes naturais como pó de araruta, manteiga de karité, óleo de amêndoas e pigmentos cosméticos minerais em pó. Como essas matérias-primas, em geral, são comercializadas, sob encomenda, em quantidades bastante superiores às necessárias para a produção de uma única base (cerca de $10 \mathrm{~g}$ ), por exemplo, o ideal é que os estudantes façam uma compra coletiva e rateiem os gastos. Considerando que os estudantes regularmente matriculados em Maquiagem e Caracterização, entre os anos de 2007 e 2011, conseguiram adquirir o conjunto de maquiagens necessárias e apesar das maquiagens artesanais viabilizarem a realização de vários exercícios práticos, elas possuem a validade inferior às maquiagens industrializadas, têm menor capacidade de fixação e suportam menos o calor de refletores, não investimos nessa produção caseira.

Atualmente, a elaboração de uma maquiagem artesanal com ingredientes naturais, para além da economia, também está associada à conscientização em relação à proteção do meio-ambiente, à fuga do uso de produtos de origem animal e ao conhecimento da procedência daquilo que se consome. De acordo com Eloisa Toguchi, uma das importantes especialistas em maquiagens artesanais na atualidade e proprietária da Lá do Mato - Saboaria Natural, em entrevista concedida a Camila Honorato ${ }^{4}$, um dos perigos do consumo indiscriminado de cosméticos industrializados é que seus fabricantes são pouco transparentes.

Apesar do programa do componente Maquiagem e Caracterização não ter contemplado amplamente a produção de maquiagens artesanais, foram feitos alguns exercícios com maquiagens alternativas, utilizando mel e corantes para a elaboração de sangue comestível, por exemplo, e gelatina incolor culinária com base facial para texturizar a pele, ao invés de látex, e criar o efeito de cicatriz de queimadura. Assim, foram utilizados tanto produtos naturais como industrializados nas criações.

O segundo desafio desse componente de quatro créditos acadêmicos, com 72 horas/aula divididas em 18 encontros ao longo de cada semestre letivo, foi justamente a otimização do tempo para o melhor aproveitamento das aulas. A solução encontrada, no caso, foi o estabelecimento e cumprimento de um cronograma preciso, sujeito a pequenas alterações, assentido pelos estudantes desde a primeira aula.

O terceiro desafio foi a busca de estratégias para garantir a interdisciplinaridade, fundamental no processo de ensino-aprendizagem. No caso desse trabalho, a interdisciplinaridade foi efetuada entre os seguintes componentes: Maquiagem e Caracterização e Interpretação Teatral II e III, todos ministrados por mim, conforme já exposto. Embora o curso de Teatro da Furb privilegie um trabalho integrado entre as

\footnotetext{
e apontador comum, estojo de pincéis, faixa para cabelos ou arco; fixador de glitter, fixador e gel de cabelo, glitter, gloss, grampos de cabelo; lápis de sobrancelha, látex líquido, maleta de maquiagens, massa modelável de maquiagem, pente e escova de cabelo; placa e espátula para misturar maquiagens; primer facial, sangue artificial, spray fixador de maquiagem, entre outros.

4 Disponível em: <https://www.youtube.com/watch?v=pXcHWQ_ouXl>. Acesso em: 31 ago. 2018.
} 
disciplinas, com o objetivo de garantir uma prática totalizadora dos conhecimentos, especialmente nas últimas fases, cuja interdisciplinaridade está prevista nas ementas das disciplinas Prática de Montagem, Interpretação Teatral, Preparação Corporal para a Cena e Preparação Vocal para a Cena, esse trabalho interdisciplinar nas primeiras fases foi uma opção minha, em comum acordo com os estudantes matriculados regularmente no curso, pois não estava explicitado em seu no Projeto Pedagógico. De todo modo, considero que esse diálogo entre os componentes foi fundamental para os resultados positivos alcançados tanto no projeto de maquiagem e caracterização para um personagem dramático, alinhado no mesmo semestre letivo com Interpretação Teatral II, como no treinamento com máscara neutra, afinado com Interpretação Teatral III no semestre subsequente.

Os conhecimentos obtidos foram visivelmente utilizados e aprofundados em outros componentes curriculares ao longo do curso; além disso, serviram de subsídio para pesquisas teórico-práticas efetuadas em espetáculos de conclusão de curso, como se pode conferir no TCC de Kriséven Campana, sob minha orientação, intitulado Figurino e Maquiagem: a influência na construção dos personagens do espetáculo 'Acordo para mudar de casa'.

O quarto desafio foi a realização das aulas em um espaço físico adequado às necessidades do componente, ou seja, um ambiente tranquilo e silencioso tanto para aulas expositivas dialogadas, como para as aulas práticas de maquiagem teatral, como para a confecção dos moldes dos rostos dos estudantes. Para conciliar uma sala de aula tradicional, compartilhada com outros cursos e disciplinas, com a prática da maquiagem, a estratégia acertadamente utilizada pelo Departamento de Teatro, na ocasião, foi instalar na sala 110 do Bloco S, no caso, além de um retroprojetor no teto, direcionado para o quadro, espelhos com lâmpadas de camarim, bancadas de madeira retráteis nas paredes laterais e cortinas para cobrir os espelhos quando eles não estivessem em uso. Se tais espelhos de meia parede não tivessem sido instalados, uma alternativa provisória seria a utilização de espelhos individuais de mesa. Cabe destacar que a S-110, embora bastante adequada e próxima dos banheiros do bloco, ao menos até 2014, ainda carecia da instalação de uma pia para atender todas as demandas dos exercícios práticos de maquiagem teatral. A confecção dos moldes, por sua vez, requer, além de um ambiente calmo, uma sala arejada, muito próxima de um tanque e/ou pia, equipada com um lixeiro grande, uma mesa de pelo menos $1,60 \mathrm{~m}$ de comprimento e/ou uma maca e um ventilador à disposição. Diante disso, as aulas destinadas à confecção da face cast foram realizadas em uma das salas de aula do curso de Artes Visuais, no piso térreo do bloco R, munidas de grandes mesas de madeira e tanques.

O quinto grande desafio ao assumir Maquiagem e Caracterização na Furb foi a carência de referências bibliográficas em língua portuguesa para a preparação das aulas, conforme observado por outros professores da área, como, por exemplo, Monica Magalhães (2009), no artigo Caracterização teatral: uma arte a ser desvendada, e por José Roberto Santos Sampaio (2015), em sua tese doutoral intitulada Maquiagem teatral: 
uma experiência metodológica de ensino na licenciatura em teatro. A primeira solução encontrada foi recorrer a alguns livros em língua inglesa, que prontamente foram adquiridos pela Furb para incrementarem 0 acervo de sua biblioteca, dentre eles destacam-se, entre outros: Theatrical make-up (1984) de Bert Broe e Stage makeup (2001) de Richard Corson e James Glavan. Apesar do livro Maquiagem (2004) de Duda Molinos não ser voltado para o teatro, o trabalho igualmente foi tomado como referência do componente curricular, pois fornece informações basilares sobre os fundamentos e técnicas de maquiagem social e, especialmente, corretiva. De todo modo, o trabalho de pesquisa e a confecção de um material próprio para a condução do componente foi imprescindível. O material audiovisual elaborado para a realização das aulas de Maquiagem e Caracterização contempla os elementos básicos da maquiagem e suas respectivas funções.

\section{OS DEZ ELEMENTOS BÁSICOS DA MAQUIAGEM TEATRAL}

O primeiro elemento básico da maquiagem é a base, seja ela líquida (cremosa), com a cobertura mais leve; em bastão, tipo pan stick / stick foundation; ou compacta, o pan cake, com cobertura mais pesada. As principais funções da base, comercializadas, sobretudo, em tons de bege, castanho e marrom, são: pigmentar a pele, suavizar as feições faciais e ajudar a criar uma impressão visual da personagem.

O pan cake, idealizado na Era de Ouro de Hollywood pelo maquiador e empresário russo Max Factor (1872-1938) para ser usado no cinema devido sua cobertura densa que permite cobrir várias imperfeições da pele e por ser mais resistente à transpiração dos atores e ao calor dos holofotes, em 1935 passou a ser comercializado em grande escala e é um produto utilizado ainda hoje, especialmente no teatro, em várias cores, dentre elas, para além dos diferentes tons de bege, amarelo, azul, branco, laranja, preto, verde, vermelho, entre outras. No entanto, para a maquiagem social, cotidiana, ele "saiu de moda", digamos assim, pois sua aplicação com esponja umedecida demanda alguns cuidados para um efeito uniforme; além disso, atualmente, há outros tipos de base que conferem um efeito mais natural. Cabe mencionar que o Sr. Max Factor contribuiu amplamente com o desenvolvimento da indústria cosmética, pois, além de inventar o pan cake e o comercializar a partir de 1935, conforme já mencionado, ele popularizou o termo maquiagem. Sendo que, em 1916 começou a vender lápis de olho e sobrancelhas, inaugurando a venda desses produtos fora da indústria cinematográfica; em 1953 lançou o pó compacto (crème puff powder compact) e em 1954 difundiu o corretivo em bastão.

O segundo elemento básico da maquiagem é o corretivo, igualmente disponível no mercado em creme, em bastão, ou compacto. As principais funções do corretivo são atenuar as olheiras, diminuir linhas de expressão e disfarçar pequenas imperfeições, pois são aliados em estratégias de camuflagem e neutralização. Em relação à ordem de aplicação do corretivo, há maquiadores que optam por aplicar o corretivo antes da base 
e outros após a base. Particularmente, prefiro aplicar o corretivo antes da base; pois me parece que assim a suavização de olheiras, manchas e tatuagens, por exemplo, é mais eficaz. Além de corretivos em tons de bege e marrom, também há corretivos coloridos, tais como o verde, recomendado para disfarçar rosáceas e espinhas; 0 amarelo, apropriado para cobrir olheiras arroxeadas; o vermelho, indicado para disfarçar manchas brancas; o lilás, recomendado para amenizar sardas e manchas escuras; entre outras cores.

A dúvida frequente sobre qual cor de corretivo usar pode ser facilmente sanada com o uso do círculo cromático. Aliás, essa ferramenta de trabalho é recomendada para todos os profissionais que lidam com cores; no caso de um espetáculo teatral, não só nas maquiagens como também nos figurinos e nos demais aspectos visuais. O círculo cromático indica a relação entre as cores, permite sobreposição e contribui para o estudo da aplicação delas de forma harmônica. Assim, por exemplo, é possível confirmar que o resultado da sobreposição da cor amarela na roxa é a cor marrom; portanto, o corretivo amarelo é o mais indicado para disfarçar olheiras. O corretivo colorido, de cobertura mais potente, neutraliza a cor que se pretende camuflar.

O modo correto de aplicar o corretivo, para um efeito mais natural, é formando um triângulo invertido da região em baixo dos olhos até as maçãs do rosto e não formando uma meia-lua abaixo dos olhos. Sendo que, o triângulo, o círculo e o quadrado são as formas planas básicas. No caso das maquiagens, estas formas geométricas são, de acordo com o prof. Sampaio, "[...] suportes para o entendimento do formato do rosto e facilitadores da concepção da maquiagem a ser realizada, para a obtenção de traços retos, curvos e mistos, elaborando-se uma moldura que se que adeque às características e emoções dos personagens." (2015, p. 145)

O terceiro elemento básico da maquiagem é o pó facial, solto ou compacto, comercializado, comumente, em tons de bege, branco e translúcido, foscos ou brilhantes. Uma das principais funções do pó é fixar a maquiagem, além de tirar o brilho e a oleosidade da pele. Considerando que ele também confere pigmentação para a pele, deve ser utilizado em sintonia com a base.

O quarto elemento da maquiagem é o blush (conhecido antigamente como rouge), comercializado, em geral, na forma de pó (compacto), em creme e em mousse, em diferentes tons de bege, marrom, vermelho, laranja e rosa. Os blushes, pigmentam a pele e, especialmente os foscos, ajudam a dar a sensação visual de aumentar ou diminuir volumes e profundidades, ou seja, ocultar angulações faciais. Além disso, ajudam a caracterizar a personagem, contribuindo, por exemplo, com seu ar saudável ou doentio.

O blush é um ingrediente bastante utilizado na maquiagem corretiva, ou seja, no jogo de claro e escuro para iluminar ou camuflar certas regiões do rosto. Na maquiagem social, são os truques utilizados para compensar o que se acredita ser um "defeito" chamando a atenção para o que seriam os pontos fortes. A maquiagem teatral não tem como finalidade embelezar o ator; contudo, o domínio da maquiagem corretiva é 
imprescindível para a elaboração de determinadas maquiagens, como, por exemplo, de Drag Queen. Em 2001, no processo de criação do espetáculo Noite de Reis, de W. Shakespeare, sob direção de José R. Faleiro, utilizei essa técnica para a criação das maquiagens dos personagens Viola, representada por mim, e Sebastian - 0 irmão gêmeo de Viola, representado por Edmundo Wagner.

O quinto elemento da maquiagem é a sombra. As sombras para os olhos são comercializadas em uma gama gigantesca de cores, foscas, brilhantes e cintilantes, em pó (compactas e soltas), em creme e em mousse. Elas modelam, destacam, sombreiam e iluminam os olhos. Considerando que os olhos são um importante ponto de comunicação entre os atores e os espectadores, o uso de sombras é bastante importante.

$\mathrm{O}$ sexto elemento da maquiagem é o lápis para os olhos. Esse material é fundamental para destacar e gerar alguns efeitos como, por exemplo, diminuir ou aumentar o tamanho dos olhos. 0 contorno das linhas internas dos cílios é o traço comumente aplicado na maquiagem social e/ou teatral; esse traço confere profundidade ao olhar. Mas, os olhos também podem ser marcados com delineadores e sombras diluídas em água, segundo o efeito almejado.

O sétimo elemento básico é o lápis para as sobrancelhas. $O$ desenho das sobrancelhas contribue para a construção da personagem, uma vez que de acordo com seu formato remetem às qualidades positivas ou negativas. Sobrancelha piramidal pode caracterizar um personagem deprimido, abatido; sobrancelhas arredondadas e arqueadas definem um olhar maravilhado, espantado, duvidoso, curioso e/ou ingênuo; sobrancelhas arredondadas e caídas lembram preocupação, aflição, ansiedade; sobrancelhas arqueadas assinalam um olhar questionador; sobrancelhas arqueadas e elevadas marcam um olhar arrogante, desdenhoso e/ou vilão; e assim por diante.

O oitavo elemento da maquiagem é a máscara e/ou gel para os cílios, comercializada nas cores preta, marrom, transparente ou colorida. Os formatos dos pincéis das máscaras, e os cílios postiços, ajudam a destacar, dar volume, curvar e/ou alongar os cílios.

O nono elemento da maquiagem é o lápis de boca, que, além delimitar a área onde será aplicado 0 batom, também contribui para que a boca permaneça pigmentada por mais tempo e dificulta que o batom escorra. Assim como o desenho das sobrancelhas, o formato e o tamanho da boca também ajudam a compor a personagem. Uma boca muito fina lembra rispidez, solidão e/ou crueldade; lábios carnudos e com o arco-docupido bem definido remetem à sensualidade; lábios caídos caracterizam tristeza etc.

O décimo e último elemento básico da maquiagem é o batom que, em harmonia com o lápis e/ou gloss, contribui para aumentar ou diminuir o volume dos lábios. O batom, além de colorir os lábios, pode ser utilizado, 
caso seja necessário, como blush, delineador, e até mesmo como corretivo. Por exemplo, em uma maquiagem masculina, para anular o tom azulado da barba e "neutralizar" a pele, na falta de um corretivo laranja, é possivvel usar um batom laranja opaco.

\title{
A IMPORTÂNCIA DAS CORES NA MAQUIAGEM TEATRAL
}

A criação da maquiagem e da caracterização da personagem remete, inevitavelmente, às cores. $A$ escolha das cores das maquiagens deve levar em conta, além do efeito fosco (matte) ou brilhante e do tom da pele do ator, a cor que a personagem demanda; pois a cor é a primeira característica visual da maquiagem e da cenografia como um todo. As cores contam uma história e auxiliam na caracterização da idade e do status do personagem. Além disso, a cor da maquiagem será influenciada tanto pela iluminação como pela movimentação dos atores em cena. Segundo as palavras da cenógrafa inglesa Pamela Howard,

\begin{abstract}
Desde os tempos antigos, a cor foi usada para demonstrar idade e status, tanto no palco como fora dele, e ainda hoje é um fator importante na narração de uma história. [...] A arte de um cenógrafo também envolve direcionar o olhar do espectador por meio do entendimento da história ou do texto, expressando isso mediante composição e cor. Quando abstraídas da narrativa, essas indicações cênicas devem ser capazes de existir como um trabalho artístico. No contexto do espetáculo, o mobiliário, os objetos cênicos e os figurinos falam a respeito da profissão, condição de vida, clima etc., expressos por meio de tecidos, padrões e decorações, iluminando o contexto histórico e sociológico do drama. (2015, p. 144-145).
\end{abstract}

Em linhas gerais, as cores podem ser divididas em cor luz e cor pigmento. Sendo que, um objeto pode mudar de cor dependendo da luz que incide sobre ele. Portanto, é muito importante que a maquiagem seja experimentada junto com o figurino e com a iluminação.

A partir de uma ampla busca, sobretudo na internet, levantei diversas associações e possibilidades de percepção de doze cores, conforme apresento a seguir:

a) azul: calma, frio, espiritualidade, pureza, verdade, tristeza, segurança, força;

b) laranja: alegria, animação, vivacidade, criatividade, confiança;

c) vermelho: agressividade, paixão, sexo, sangue, irritação, poder, juventude, coragem;

Revista "O Teatro Transcende" Departamento de Artes - CCEAL da FURB - ISSN 2236-6644 - Blumenau, Vol. 23, № 1, p. 21 - 31, 2018 - Edição Especial dos 45 Anos de Artes na FURB. 
d) amarelo: dinheiro, alegria, felicidade, jovialidade, covardia, clareza, calor, otimismo;

e) rosa pink: amor, fantasia, imaginação, romantismo.

f) verde escuro: jovialidade, imortalidade, eternidade, renascimento, ciúmes, inveja;

g) verde claro: descanso, alívio, tranquilidade, crescimento, saúde;

h) púrpura: pesar, tristeza, místico, majestoso, imaginativo, sabedoria;

i) cinza: neutralidade, depressão, negatividade, sombra, equilíbrio, calma;

I) marrom: terra, popular, pobreza.

m) branco: paz, harmonia, verdade, pureza, inocência, passividade.

n) preto: formalidade, poder, melancolia, tristeza, trágico, escuridão, morte.

As cores podem ser divididas em frias e quentes. As cores quentes, como o vermelho, o laranja e o amarelo, por exemplo, remetem à luz do sol, ao fogo; elas parecem movimentar-se pelo espaço e atraem rápido a atenção dos espectadores, pois são estimulantes, excitantes. Mas, elas também remetem a ideia de contenção e proximidade; portanto, deve-se ter em conta que o que for pintado com cores quentes, seja nas maquiagens e/ou figurinos e/ou cenários, pode parecer ter seu tamanho menor do que é de fato pela impressão de proximidade. Em linhas gerais, as cores quentes são apropriadas para cenas intensas emocionalmente e comédias; contudo, devem ser aplicadas com cautela e coerência, pois em excesso podem irritar os espectadores.

As cores frias, por sua vez, como o azul, o verde e a violeta, por exemplo, remetem às águas profundas, às sombras das árvores; elas parecem ir sumindo aos olhos do espectador e são menos chamativas, são tranquilizantes. Como elas dão a sensação de amplitude, deve-se ter em conta que o que for pintado com cores frias parece aumentar de tamanho pela impressão de distância. Via de regra, as cores frias são indicadas para dramas e tragédias e, em excesso, podem desanimar os ânimos dos espectadores.

Por meio da tarefa extraclasse de organizar em uma pasta imagens retiradas da internet, de revistas, jornais e/ou catálogos, de rostos maquiados e de pessoas que tenham traços marcantes, nas aulas de Maquiagem e Caracterização, os estudantes da Furb foram sempre estimulados a criarem, como diz Howard, "[...] uma paleta individual de cores" (2015, p. 145). 


\section{CONSIDERAÇÕES FINAIS}

A experiência, entre os anos de 2007 e 2011, com o componente curricular Maquiagem e Caracterização evidenciou que o ensino da automaquiagem é de suma importância para atores em formação e seu aprendizado é extremamente prazeroso. Nas aulas práticas, os estudantes foram avaliados em relação ao uso adequado dos elementos da maquiagem de acordo com suas funções, cumprimento das etapas de aplicação de maquiagem e domínio das técnicas apresentadas em sala.

A maquiagem é fundamental para o processo de composição da personagem, independente da poética adotada. Este elemento precisa ser trabalhado e deve estar em harmonia com os demais aspectos visuais do espetáculo, tais como o figurino, a iluminação e a cenografia como um todo; pois, nesse caso, está a serviço de um espetáculo cênico. Dentro dessa lógica, o trabalho final, solicitado aos estudantes, consistia em um projeto de maquiagem e caracterização, tendo como referência uma peça teatral pré-existente. Nesses projetos, foram considerados os seguintes critérios de avaliação: escolha e descrição da maquiagem e caracterização adequadas ao tema da peça escolhida, ao personagem, ao período histórico, às circunstâncias dadas pelo dramaturgo etc.; apresentação de imagem ilustrativa (desenho) e amostras (tecidos, por exemplo).

\section{REFERÊNCIAS}

BROE, Bert. Theatrical makeup. London: Pelham Books; New York: Beaufort Books: Distributed by Kampmann, c1984.

CORSON, Richard; GLAVAN, James. Stage makeup.9th ed. Boston, MA: Allyn and Bacon, 2001.

HOWARD, Pamela. O que é cenografia? São Paulo: Sesc São Paulo, 2015.

MAGALHÃES, Monica. Caracterização teatral: uma arte a ser desvendada. In: TELLES, Narciso, FLORENTINO Adilson. Cartografias do ensino de teatro. Uberlândia: Edufu, 2009, p. xx

MOLINOS, Duda. Maquiagem. 7. ed. São Paulo: Ed. SENAC, 2004.

SAMPAIO, José Roberto Santos. Maquiagem teatral: uma experiência metodológica de ensino na licenciatura em teatro. Tese (doutorado). Programa de Pós-Graduação em Artes Cênicas da Universidade Federal da Bahia. Salvador, 2015.

TOGUCHI, Eloísa. Retrato\#1: Eloísa Toguchi fala sobre artesanato e cosméticos. Entrevistadora: Camila Honorato. São Paulo. Disponível em: <https://www.youtube.com/watch?v=pXcHWQ_ouXI>. Acesso em: 31 ago. 2018. 